\title{
Structural and functional abnormalities of penile cavernous endothelial cells result in erectile dysfunction at experimental autoimmune prostatitis rat
}

\author{
Tianrun Huang ${ }^{\dagger}$, Guangchun Wang ${ }^{\dagger}$, Yangyang Hu, Heng Shi, Keyi Wang, Lei Yin ${ }^{*}$ and Bo Peng ${ }^{*}$ (1)
}

\begin{abstract}
Background: There is growing recognition of the association of CP/CPPS accompany with ED. However, the specific mechanism of action remains unclear. The aim of this study was to investigate structural and functional abnormalities of cavernous endothelial cells in EAP rat, which may result in the ED.

Methods: we use rat prostate protein extract supplemented with immunoadjuvant to induce EAP rat, ICP and MAP were measured and inflammatory factor infiltration, Akt, eNOS, AR, nNOS and iNOS in the corpus cavernosum were tested. Subsequently, the normal rat and EAP rat cavernosum endothelial cells were purified by MACS, and the metabolism, oxidative stress, MMP, Akt, eNOS, AR and iNOS were evaluated.

Results: The EAP rat model was successfully constructed. The ratio of max ICP/MAP in EAP rat was significantly lower and TNF-a infiltration in corpus cavernosum was significantly higher than normal rats. Besides, Akt, eNOS and AR were decreased, iNOS was significantly increased. The growth and metabolism of endothelial cells in the EAP rats corpus cavernosum decreased and inflammatory factor mRNA was increased and intracellular oxidative stress was also increased significantly. The MMP of EAP rats cavernosum endothelial cells decreased and the expression of Akt, eNOS and AR were also significantly decreased, iNOS was significantly increased.

Conclusion: The prostate suffer local inflammatory infiltrate and promotes cytokines infiltrated into corpus cavernosum caused the oxidative stress increases and the metabolism or MMP decreases. In addition, AR, Akt and eNOS expression and phosphorylation are also reduced, thereby inhibiting the diastolic function of the corpus cavernosum, resulting in decreased erectile function.
\end{abstract}

Keywords: Prostatitis, Erectile dysfunction, Endothelial cells

\section{Introduction}

Prostatitis is the most common urinary system disease in men under 50 years of age [1]. The clinical manifestations of prostatitis are complex and diverse. Symptoms such as Chronic prostatitis/chronic pelvic pain syndrome (CP/CPPS) are the most common. It is reported that $15 \%$ of men experience prostatitis and suffer some symptoms during their lifetime [2],

\footnotetext{
*Correspondence: yltale@126.com; pengbo6908@163.com

${ }^{\dagger}$ Tianrun Huang and Guangchun Wang contributed equally to this work Department of Urology, Shanghai Tenth People's Hospital, Tongji University School of Medicine, NO 301 Yanchang Road, Shanghai 200072, People's Republic of China
}

which could significantly reduce their quality of life [3]. With the focus of prostatitis symptoms, more and more studies have shown that there is a correlation between prostatitis symptoms and sexual dysfunction, especially erectile dysfunction (ED). Epidemiological studies suggest that the overall prevalence of sexual dysfunction in patients with prostatitis is between 60 and $75 \%$, and $35-60 \%$ of patients have ED or ED couple with other sexual dysfunction [4, 5]. Chung etal found that prostatitis patients were 3.62 times more likely to have ED than general population [6]. Given the high incidence of CP/CPPS in young male populations, so CP/CPPS is considered to be the most 
common cause of ED in young men [4-6], but the underlying mechanism between prostatitis and ED still unclear.

The penile is consisted of 3 erectile columns, the 2 corpora cavernosa and the corpus spongiosum, as well as the columns' enveloping fascial layers, nerves, lymphatics, and blood vessels, all covered by skin. The corpora cavernosa contain erectile tissue and are each surrounded by the tunica albuginea, a dense fibrous sheath of connective tissue with relatively few elastic fibers. Along the inner aspect of the tunica albuginea, flattened columns or sinusoidal trabeculae composed of fibrous tissue and smooth muscle surround the endothelial-lined sinusoids (cavernous spaces) [7, 8]. Penile erection is a neurovascular phenomenon that depends upon neural integrity, a functional vascular system, and healthy cavernosal tissues. Nitric oxide (NO), which was produced by endothelial nitric oxide synthase (eNOS) and neuronal nitric oxide synthase (nNOS) under physiological conditions, appears to be the principal neurotransmitter causing penile erection. The release of NO increases the production of cyclic guanosine monophosphate (cGMP), which relaxes cavernosal smooth muscle, leading to arterial inflow increase and the sinusoids within the corpora cavernosa distend with blood. As a result, intracavernous pressure increases and has an erection. At present, the signaling pathways on whether prostatitis participates and reduces erectile function have gradually attracted the attention of scholars. Shoskes et al. found that prostatitis can lead to arterial stiffness associated with NO-mediated endothelial dysfunction [9]. Endothelial dysfunction can inhibit endothelium-dependent vasorelaxation (EDR) [10] and can also strengthen arterial contractions [11]. However, whether prostatitis damage to the corpus cavernosum endothelial cells could causes ED are still unclear.

We have previously established a rat model of experimental autoimmune prostatitis (EAP) to verify the decline in erectile function in EAP rats [12]. On this basis, we concentrate on Structural and functional abnormalities of penile cavernous endothelial cells at experimental autoimmune prostatitis rat.

\section{Materials and methods}

\section{Experimental animal}

Male Sprague-Dawley rat, 6-8 weeks and 180-240 g, was purchased from the animal center affiliated to Nanjing Medical University. All rats breed in constant optimal temperature and humidity for a normal 12-h light and dark cycle. The survey is in line with the "Guidelines for the Care and Use of Laboratory Animals" published by the National Institutes of Health. All procedure approved by the Animal Science Committee of Tongji University.

\section{Establishment of a rat model of EAP}

The EAP model was as previous study reported [12]. Ten rats were used for preparing autologous prostate tissue homogenate supernatant (PTHS). And the rest of 40 rats were randomly divided into EAP model group and control group (20 rats each). In EAP model group, each rat was administered $1.0 \mathrm{~mL}$ isovolumetric mixture of PTHS $(20 \mathrm{mg} / \mathrm{mL})$ and Freund's complete adjuvant by multipoint subcutaneous injection; meanwhile, $0.5 \mathrm{~mL}$ of a pertussis-diphtheria-tetanus vaccine was performed by intraperitoneal injection. In control group, each rat was injected with isovolumetric PBS instead. After three times of immunizations administered at days 0,15 , and 30, the rat model of EAP was established.

\section{Assessment of erectile function}

At 45th day after the first immunisation, the max intracavernous pressure (ICP) and the ratio of $\max \mathrm{ICP} /$ mean systemic arterial pressure (MAP) were used to assess erectile function, which have been described previously [12]. The erectile response was elicited by electrical stimulation of the cavernous nerve and quantified by calculating the max ICP/MAP. Rats were anesthetized with intraperitoneal sodium pentobarbital $(40 \mathrm{mg} / \mathrm{kg}$, Sinopharm Chemical Reagent Co. Ltd., Shanghai, China). The pressure was measured and recorded using a windows computer programcontrolled multiplying channel physiograph and analyzed using a BL-420 V pressure transducer system (Chengdu Implement Company, Chengdu, China). For each rat, electrical stimulations of the cavernous nerve were stimulated at a frequency of $12 \mathrm{~Hz}$ and using a pulse width of $5 \mathrm{msec}$. Stimulations were performed in triplicate at $5 \mathrm{~V}$ for $30 \mathrm{~s}$ with intervals of $5 \mathrm{~min}$ between subsequent stimulations. The mean max ICP/MAP values were considered to represent the erectile function of rats.

\section{Inflammatory infiltration of rat prostate and corpus cavernosum}

Rats was sacrificed at 45th day after the first immunisation (about 87-101 days). Rats were euthanized using intraperitoneal sodium pentobarbital $(150 \mathrm{mg} / \mathrm{kg})$ and immediately remove the penis and prostate tissue. A portion of the corpus cavernosum and prostate tissue was fixed overnight in $4 \%$ paraformaldehyde, and the remainder was stored in liquid nitrogen for further analysis. The fixed tissue was then dehydrated in $70 \%$ ethanol and embedded in paraffin. These paraffin-embedded samples were cut into sections, and then deparaffinized and subjected to HE staining. After dyeing for $15 \mathrm{~min}$ in the hematoxylin dyeing tank, the running water was slightly washed with hematoxylin 1-3 s, 1\% hydrochloric 
acid ethanol for $1 \mathrm{~min}$, double distilled water for 10-30 $\mathrm{s}$, and quickly placed in $0.5 \%$ eosin for $3 \mathrm{~min}$, double steaming. The water is rinsed and dehydrated.

Immunohistochemistry of TNF- $\alpha$, after washing three times with PBS, $50-100 \mu \mathrm{l}$ of normal goat serum was added dropwise, incubated at room temperature for 20 min until blocking, and then the first antibody was dropped into a wet box and incubated for $2 \mathrm{~h}$. After washing three times with PBS, $50 \mu \mathrm{l}$ of enhancer was added and incubated in a wet box for $30 \mathrm{~min}$ at room temperature. The secondary antibody was incubated for 30 min after washing three times with PBS. It was then washed with PBS and stained with DAB, stained with hematoxylin for $10 \mathrm{~min}$ and dehydrated and sealed. The expression of TNF- $\alpha$ in the tissues was observed under a light microscope.

\section{Measuring oxidative stress levels}

SOD activity, MDA and NO levels were used to evaluate oxidative stress state. The SOD activity, MDA and NO levels was measured by using commercial kits (Nanjing Jiancheng Bioengineering Company, Nanjing, China) following the manufacturer's instructions.

\section{Isolation and purification of corpus cavernosum endothelial cells}

The cavernous endothelial cells of normal control rats and EAP rats were isolated and purified by enzymatic digestion and magnetic activated cell sorting (MACS). Rats were anesthetized by intraperitoneal injection of $3 \%$ pentobarbital sodium. After incision of the foreskin and fascia, removal of tissues such as the urethra, dorsal veins and artery, the penis was quickly cut and submerged in pre-cooled phosphate buffered saline containing $100 \mu \mathrm{g} / \mathrm{mL}$ penicillin and streptomycin, and rinsing and removal of blood coagulation Piece. The penile tissue was then placed under a microscope (Nikon, Model C-DSD230, Japan) to remove the tunica albuginea, and the corpus cavernosum was cut into small pieces (1 $\mathrm{mm}^{3}$ ). Subsequently, $200 \mathrm{U} / \mathrm{mL}$ collagenase IV (GIBCO, 17104019, USA) was added to Hanks Balanced Salt Solution containing $\mathrm{Ca}^{2+}$ and $\mathrm{Mg}^{2+}$ (Invitrogen, 14025092 , USA) and digested on a $37^{\circ} \mathrm{C}$ shaker. Minute. The digestive juice containing the cells is then collected and replenished with fresh collagenase IV-containing digestive juice until the digestive corpus cavernosum is completely digested. Add $0.25 \%$ trypsin (GIBCO, 15050065 ) and $1 \mathrm{mg} / \mathrm{mL}$ DNase I (Rubio, D3212, China) without EDTA in the collection of collagenase IV containing cells, continue digestion for $5 \mathrm{~min}$, and then add $20 \%$ fetal The digestion was terminated by EGM-2 medium (LONZA, cc-3156 \& cc-4176, USA) of bovine serum (FBS; GIBCO, 10270106, South America). The digestive juice containing the cells is filtered through a sieve to separate into individual cells. The cell pellet was collected by centrifugation at $300 \mathrm{x} \mathrm{g}$ for $10 \mathrm{~min}$, and the cells were resuspended and cultured in EGM-2 medium at $37^{\circ} \mathrm{C}, 5 \% \mathrm{CO}_{2}$. The culture flask was precoated with $1 \%$ gelatin.

When the cells grow to $80 \%$ confluence, the old culture medium in the cell culture flask is aspirated by a pipette, the cells are washed with PBS solution, $0.5 \mathrm{ml}$ of $0.05 \%$ trypsin solution containing EDTA is added, and the digested cells are observed under an inverted microscope. After the cells are retracted, the cells are no longer connected to the tablets, and then the serumcontaining medium is added to completely terminate the digestion, and then the cell suspension is gently blown. After centrifugation at $200 \mathrm{~g}$ for $10 \mathrm{~min}$, the supernatant was removed and the cell pellet was collected. The cell pellet was washed again with Buffer and subjected to cell counting. $10 \mu \mathrm{L}$ of PE mouse anti-rat CD31 (BD, 555027, USA) was added to each 107 cells for $15 \mathrm{~min}$ at $4{ }^{\circ} \mathrm{C}$. After centrifugation as above, $20 \mu \mathrm{L}$ of anti-PE MicroBeads (Miltenyi Biotec, 130-048-801, Germany) was added. Then, after incubating for $15 \mathrm{~min}$ at $4{ }^{\circ} \mathrm{C}$, the cells were washed again, resuspended in $500 \mu \mathrm{L}$ of buffer, and poured into a separation column (Miltenyi Biotec, 130-042-201) placed in a magnetic field for sorting. The CD31+ cells were sorted and adsorbed on the separation column, while the CD31- cells were eluted with the buffer. After removing the separation column from the magnetic field, the CD31+ attached to the tube wall was quickly washed with $1 \mathrm{~mL}$ of buffer, and the purified corpus cavernosum endothelial cells were obtained. Purified corpus cavernosum endothelial cells were added to EGM-2 medium and cultured at $37^{\circ} \mathrm{C}$ and $5 \% \mathrm{CO}_{2}$.

\section{Identification of endothelial cells by immunofluorescence staining}

Purified corpus cavernosum endothelial cells were cultured on coverslips placed in Millicell (Millipore, PEZGS 0816, USA). At $80-90 \%$ confluence, cells were fixed in paraformaldehyde (4\%) for $30 \mathrm{~min}$, then permeabilized with Triton X-100 for 20 min and blocked with 5\% BSA for $1 \mathrm{~h}$. Cells were incubated with primary antibodies including anti-CD31 (ab119339, 1:400), anti-vWF (ab6994, 1:400), Anti-CD90 / Thy1 (ab92574, 1:200), anti-Desmin (ab32362, 1:50) overnight at $4{ }^{\circ} \mathrm{C}$ and then incubated for $2 \mathrm{~h}$ in fluorescein-labeled secondary antibodies. Room temperature. Subsequently, the nuclei were stained with 4,6-diamidino-2-phenylindole and observed by confocal microscopy (ZEISS LSM700).

\section{Cell growth and metabolism testing}

Cell growth rate was measured using CCK-8. The cell pellet was collected, washed again with the culture medium and subjected to cell counting. Add $100 \mu \mathrm{l}$ of 
cell suspension containing the corresponding cell number to each well of a 96-well plate, set up five replicate wells in each group, and culture the 96-well culture plate in $37^{\circ} \mathrm{C}, 5 \% \mathrm{CO}_{2}$ cell incubator until the cells are attached. Discard the old culture medium, add $200 \mu \mathrm{l}$ of the complete broth of the corresponding inflammatory factor per well, and incubate at $37^{\circ} \mathrm{C}$ in a $5 \% \mathrm{CO} 2$ cell culture incubator. After $24 \mathrm{~h}, 48 \mathrm{~h}, 72 \mathrm{~h}, 10 \mu \mathrm{l}$ of CCK-8 solution was added to each well, and air bubbles were avoided as much as possible. The culture was continued for $2 \mathrm{~h}$ at $37{ }^{\circ} \mathrm{C}$ in a $5 \% \mathrm{CO}_{2}$ cell incubator and then determined by a microplate reader at $450 \mathrm{~nm}$. The absorbance at the place.

\section{Flow cytometry for cell purity}

The cells were harvested and resuspended in $100 \mu \mathrm{L}$ of PBS containing 107\% BSA and $2 \mathrm{mmol} / \mathrm{L}$ EDTA per $10^{7}$ cells. $10 \mu \mathrm{L}$ of PE mouse anti-rat CD31 was added to the suspension, and the cells were incubated for $10 \mathrm{~min}$ at $4{ }^{\circ} \mathrm{C}$ in the dark. Finally, the cells were washed, resuspended in $500 \mu \mathrm{L}$ of buffer and analyzed by flow cytometry (BD, inflow, cell sorter, Franklin Lakes NJ, USA).

\section{Flow cytometry of changes in mitochondrial membrane potential (MMP)}

MMP was measured using fluorescent dye JC-1 (Yeasen, 40706 ES60, Shanghai). Briefly, after washing the corpus cavernosum cells of normal control rats and EAP rats with PBS, JC-1 was added to the cultured cells for 30 $\min$ at $37^{\circ} \mathrm{C}$ in the dark. Fluorescence intensity was estimated using BD FACS Canto II at $485 \mathrm{~nm}$ excitation and $590 \mathrm{~nm}$ emission. CCCP treated cells lasted for $20 \mathrm{~min}$ as a positive control.

\section{Detection of TNF- $\alpha$, IL-1 $\beta$, IL-6 and AR, eNOS and AKt mRNA in ESP rat corpus cavernosum endothelial cells by RT-qPCR}

Total RNA was extracted from tissue samples using TRIzol and concentrations and mass were measured. The mRNA was synthesized into cDNA and used as a template for qPCR. The reaction consisted of $10 \mu \mathrm{L}$ of 2X Real-time PCR Master Mix, $2 \mu \mathrm{L}$ of each primer and $7 \mu \mathrm{L}$ of EPC water. The reaction conditions were as follows: pre-denaturation was carried out at $95^{\circ} \mathrm{C}$ for $5 \mathrm{~min}$, denaturation at $40^{\circ} \mathrm{C}$ for $15 \mathrm{~s}$, annealing at $60^{\circ} \mathrm{C}$ for $20 \mathrm{~s}$, and elongation at $72{ }^{\circ} \mathrm{C}$ for $40 \mathrm{~s}$. The primer sequences are shown in Table 1.

\section{Western blot analysis of AR, eNOS and AKt expression in EAP rat corpus cavernosum endothelial cells}

For protein extraction, cells were washed once with PBS prior to lysis. Next, $250 \mathrm{~mL}$ of ice-cold modified RIPA buffer (Beyotime Institute of Biotechnology, Shanghai,
Table 1 The primer sequences. The GADPH was used as an internal control

\begin{tabular}{|c|c|}
\hline Item & $5^{\prime}-------3^{\prime}$ \\
\hline TNF-a-F & AGGGAATTGTGGCTCTGGGT \\
\hline TNF-a-R & AGGCCACTACTTCAGCGTCT \\
\hline$\| \mathrm{L}-1 \beta-F$ & AGAATGGGCAGTCTCCAGGG \\
\hline$I L-1 \beta-R$ & GACCAGAATGTGCCACGGTT \\
\hline IL-6-F & ATTCTGTCTCGAGCCCACCA \\
\hline IL-6-R & AGGCAACTGGCTGGAAGTCT \\
\hline AR-F & CCAGGGACCATGTTTTGCC \\
\hline AR-R & CGAAGACGACAAGATGGACAA \\
\hline Enos- $F$ & GTCTGGAGGGCTAAGCAGTC \\
\hline Enos-R & GCAAGGAAGGTTGACAGTATGC \\
\hline Akt- $F$ & GTGGACTTACCTTATCCCCTCA \\
\hline Akt-R & TTGGCTITGGTCGTTCTGTT \\
\hline GAPDH-F & GCAAGTTCAACGGCACAG \\
\hline GAPDH-R & GCCAGTAGACTCCACGACAT \\
\hline
\end{tabular}

China) was used to contain protease and phosphatase inhibitors using a cell scraper, and the cells were collected into EP tubes. Lysates were sonicated for $20 \mathrm{~s}$ ( $25 \%$ power, 0.5 cycles), centrifuged at $12,000 \mathrm{xg}$ for 30 min at $4{ }^{\circ} \mathrm{C}$, and the clarified supernatant was transferred to a new tube. Protein concentration was determined using a BCA assay (Beyotime Institute of Biotechnology).

Western blotting was performed under standard conditions. Approximately $40 \mathrm{mg}$ of protein lysate was separated on a $10-12 \%$ SDS-PAGE gel and transferred to a PVDF membrane. The PVDF membrane was then blocked with $5 \%$ milk for $2 \mathrm{~h}$ at room temperature and incubated with the primary antibody overnight. Phosphorylated eNOS (ab184154,1:500) and anti-eNOS (ab76198, 1:1000), anti- inducible nitric oxide synthase (iNOS) (ab3523, 1:500), anti-nNOS (ab5586, 1:500), Anti-CD90/Thy1(ab92574,1:1000), anti-Desmin(ab32362, 1:5000) were obtained from Abeam; anti-AR (sc-7305,1: 200) was obtained from Santa Cruz Biotechnology; phospho-Akt (4060,1:1000) and Akt antibody (9272,1: 1000) were obtained from Cell Signaling Technology. Rabbits or mouse antibodies conjugated to horseradish peroxidase (HRP) in the dark after washing for 4 times in Tris buffered saline containing $0.1 \%$ Tween 20 for $15 \mathrm{~min}$ (Thermo, 34160 and 31430) Incubate for $2 \mathrm{~h}$. Protein bands were detected by using an Enhanced Chemiluminescence system (Beyotime Institute of Biotechnology), then autoradiographed and quantified by densitometry. GAPDH (sc-32233, 1: 5000) was used as an internal reference to normalize the data. 


\section{Statistical analysis}

All statistical analyses were performed by using SPSS 20.0 (SPSS, Inc., Chicago, IL, USA). Data were presented as mean \pm standard deviation. Differences between groups were analyzed by using an unpaired Student's t-test. A value of $p<0.05$ was considered statistically significant.

\section{Results}

\section{Histopathological features of EAP rats}

Rat ventral prostate was examined. As shown in Fig. 1, in normal control rat (A), the glandular epithelium structure of prostate glands was integrated and clear without inflammatory cells infiltration and tissue hyperplasia. In EAP rat (B), the prostate duct is irregularly shaped and diffusely inhomogeneous hyperplasia, partial basal lamina was infiltrated by chronic inflammatory cells. The prostatic histopathological features of the experimental prostatitis rat model in this study are consistent with the diagnostic criteria for simulating human CP/CPPS [12].

\section{Effect of CP/CPPS on erectile function in rats}

No statistically significant difference was observed in the total body weight as well as the penis weight among EAP rats and controls. Lower max ICP/ MAP ratio was observed in the EAP group as compared to the control group. Show in Table 2.
Infiltration of TNF- $a$ and AR, eNOS, nNOS and Akt changes in EAP rats

As shown in Fig. 2, The degree of infiltration of TNF- $\alpha$ in the corpus cavernosum of EAP rats (A right) was significantly higher than that of normal rats (A left), and the expression of AR, eNOS and Akt in the corpus cavernosum of EAP rats was significantly decreased, iNOS was significantly increased (as show in Fig. $2 \mathrm{~b},{ }^{*} p<0.05$ ).

\section{Identification of cavernous endothelial cells}

The corpus cavernosum endothelial cells maintained as cobblestone-like morphology phenotype (Fig. 3a and $\mathrm{b})$. Before being sorted by immunomagnetic beads, a large number fibroblasts and smooth muscle cells mixed with $\mathrm{s}$ cavernosum endothelial cells (Fig. 3a). Flow cytometry showed that $5.81 \pm 0.17 \%$ of the cells were CD31+(Fig. 3a right) before purification. And the proportion of CD31+ after MACS increased significantly to $95.32 \pm 0.3811 \%$ (Fig. 3b right). It was further confirmed by immunofluorescence (Fig. 3c) that almost all cells observed were CD31 positive (red) in the cell membrane and vWF positive (green) in the cytoplasm. Immunofluorescence and Western blotting confirmed cells after MACS lack the express of Desmin and CD90/Thy1 which were strongly expressed in smooth muscle and fibroblast cells (Fig. 3d).
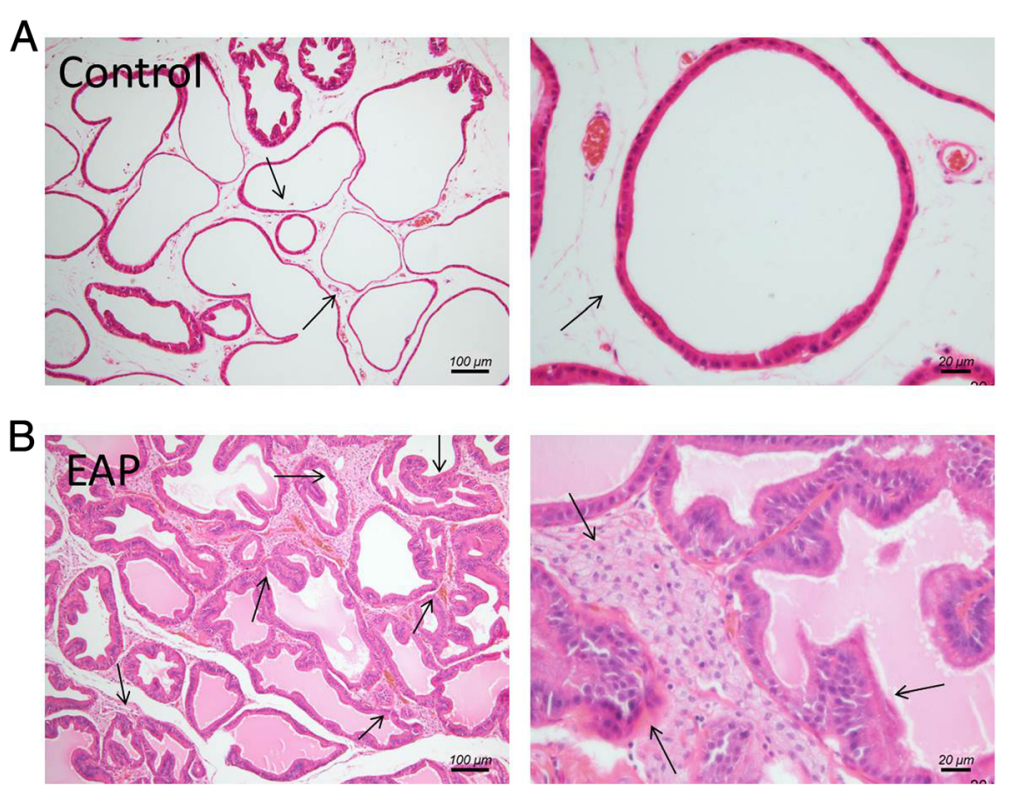

Fig. 1 Histopathological features of ventral prostate tissue in control and EAP rats. In the normal rat, the glandular epithelium structure of prostate glands was integrated and clear without inflammatory cells infiltration and tissue hyperplasia (a). In EAP rat, the prostate duct is irregularly shaped and diffusely inhomogeneous hyperplasia, partial basal lamina was infiltrated by chronic inflammatory cells (b). EAP: Experimental autoimmune prostatitis 
Table 2 Comparisons of body and penis weight, erectile function in two groups

\begin{tabular}{llll}
\hline Item & EAP & Control & $P$ value \\
\hline Body weight $(\mathrm{g})$ & $510.10 \pm 9.76$ & $515.93 \pm 8.90$ & 0.080 \\
Penis weight $(\mathrm{mg})$ & $374.09 \pm 9.22$ & $369.05 \pm 8.95$ & 0.901 \\
Max ICP $(\mathrm{mmHg})$ & $64.83 \pm 8.16$ & $94.33 \pm 4.76$ & $0.001^{*}$ \\
MAP (mmHg) & $133.78 \pm 10.31$ & $125.67 \pm 4.82$ & 0.263 \\
Max ICP/MAP & $0.48 \pm 0.03$ & $0.75 \pm 0.02$ & $0.001^{*}$ \\
\hline
\end{tabular}

${ }^{*} p<0.05$ Max ICP Max Intracavernosal Pressure, MAP Mean Arterial Pressure

\section{Changs of cell growth and oxidative stress in rat corpus cavernosum endothelial cells}

Compared with the normal control, the EAP rat corpus cavernosum endothelial cells showed a significant decrease in relative cell growth within $72 \mathrm{~h}$ (Fig. 4a). After $72 \mathrm{~h}$ of culture, the mRNA levels of TNF- $\alpha, \mathrm{IL}-1 \beta$, and IL6 in EAP rat corpus cavernosum endothelial cells were significantly increased compared with normal controls (Fig. 4b). And the NO level in the EAP rat corpus cavernosum endothelial cells was $781.0 \pm 14.19 \mu \mathrm{mol} / \mathrm{mg}$ prot, the MDA level was $3.993 \pm 0.22 \mathrm{nmol} / \mathrm{mg}$ prot, which was significantly higher than that of the normal control rat corpus cavernosum endothelial cells (NO: 182.7 \pm $13.20 \mu \mathrm{mol} / \mathrm{mg}$ prot, MDA: $2.736 \pm 0.02 \mathrm{nmol} / \mathrm{mg}$ prot); SOD level in EAP rat corpus cavernosum endothelial cells was $22.08 \pm 1.06 \mathrm{U} / \mathrm{mg}$ prot, significantly lower than that of normal control rat corpus cavernosum endothelial cells (42.97 $\pm 0.68 \mathrm{U} / \mathrm{mg}$ prot) (Fig. 4c).

\section{Changs of mitochondrial membrane potential level in rat corpus cavernosum endothelial cells}

As shown in Fig. 5, Flow cytometry showed that $90.46 \pm 0.97 \%$ cells in EAP rat corpus cavernosum endothelial cells (B) and only $0.39 \pm 0.19 \%$ of normal control rat corpus cavernosum endothelial cells (A) were in P2, indicating EAP rats mitochondrial membrane potential level was significantly decreased.

\section{AR, eNOS, AKt and iNOS in EAP rat corpus cavernosum endothelial cell decreased significantly}

As shown in Fig. 6, the levels of AR, eNOS and AKt mRNA (Fig. 6a) and protein (Fig. 6b) were significantly reduced in EAP rat cavernous endothelial cells compared to control rat. In addition, pAkt and peNOS were significantly decreased, indicating that phosphorylation of Akt

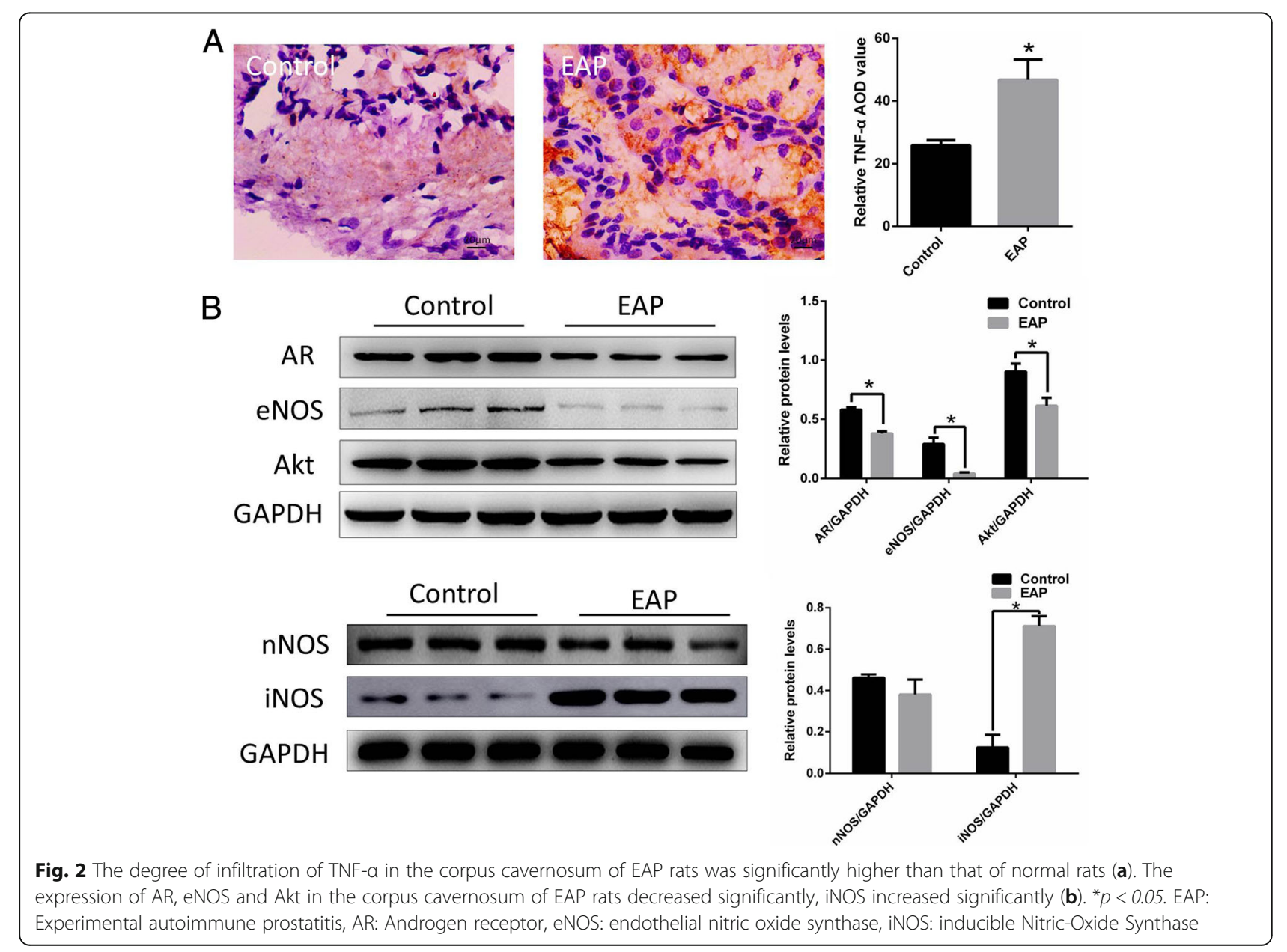



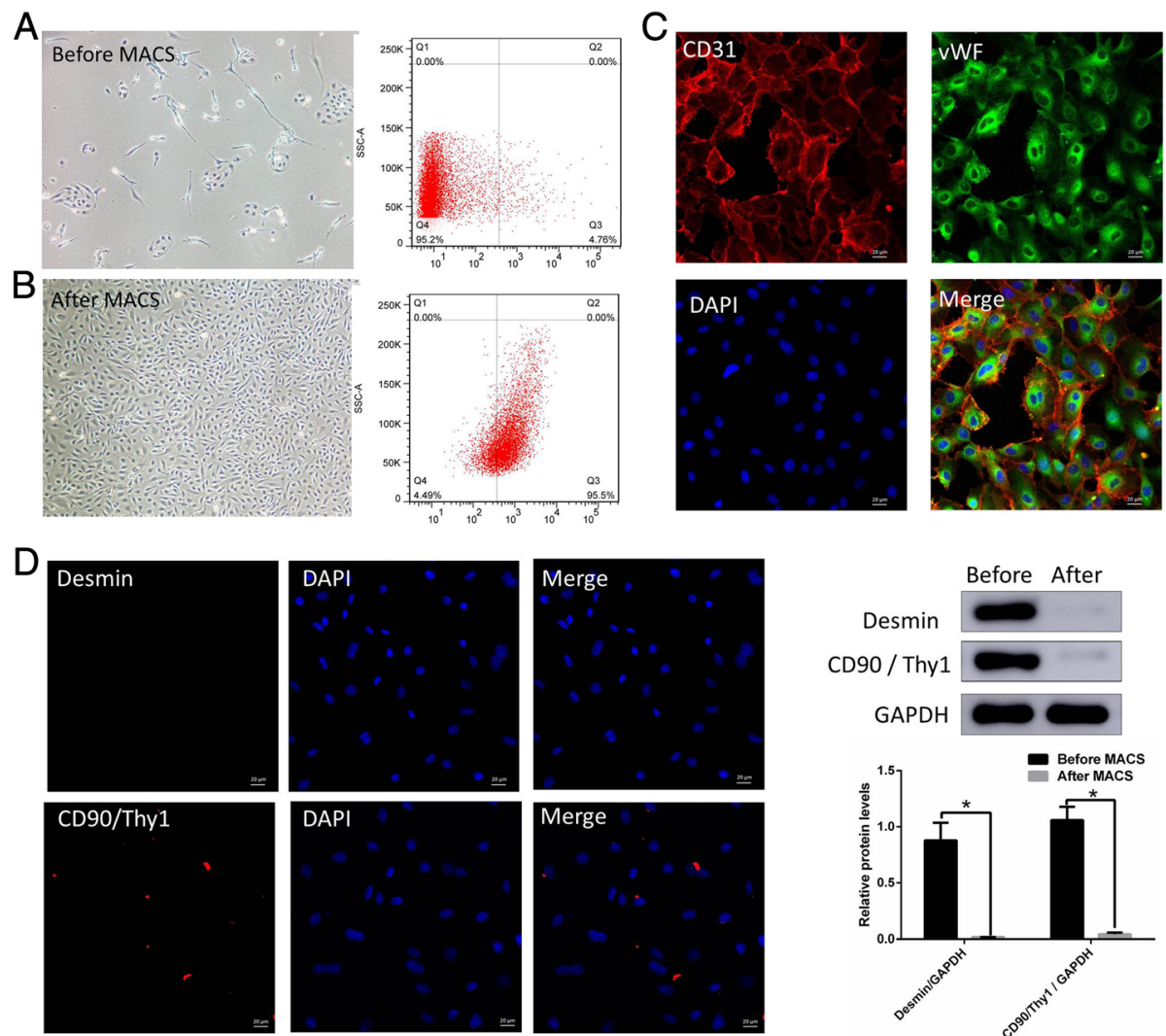

Fig. 3 Purification and identification of cavernous endothelial cells. The cobblestone-like morphology of the corpus cavernosum endothelial cells (a and $\mathbf{b}$ ). Before the sorting by immunomagnetic beads, a large number of lumps or long spindles were formed to form fibroblasts and smooth muscle cells (a left). Flow cytometry showed that $5.81 \pm 0.17 \%$ of the cells were CD31 + (a right) before purification. And the proportion of CD31 + after MACS increased significantly to $95.32 \pm 0.38 \%$ (b left). Almost all cells were CD31 positive (red) in the cell membrane and vWF positive (green) in the cytoplasm (c). Immunofluorescence (left) and Western blotting (right) confirmed cells after MACS lack the expression of Desmin and CD90 / Thy 1 which were strongly expressed in smooth muscle and fibroblast cells (d). ${ }^{*} p<0.05$. MACS: Magnetic-activated cell sorting WWF: Von Willebrand factor

and eNOS were inhibited. iNOS protein was significantly increased in EAP rat cavernous endothelial cells.

\section{Discussion}

In recent years, the correlation between chronic prostatitis and ED has also received increasing attention. Many epidemiological studies have suggested that the incidence of ED in patients with chronic prostatitis is significantly higher than in the normal population $[13,14]$ and patients with chronic prostatitis with ED are also associated with lower urinary tract symptoms [4]. Previous studies have suggested that psychological disorders caused by prostatitis play a significant role in causing ED [15-17], such as CP / CPPS induce pain, lower urinary tract symptoms, and have a negative impact on the sex life [18], but organic damaged caused by CP/CPPS was rarely reported.

Endothelial cells play an initial role in the erectile process through the eNOS-NO-cGMP pathway [19], it is important to successfully isolate and compare the differences in endothelial cell function in chronic prostatitis. Since the first report of the isolation of penile cavernous endothelial cells by tissue block implantation in 1989 [20], several methods have been applied [21] and more currently used elastic elastase digestion [8]. Theoretically, elastase does not decompose the extracellular matrix,so avoid mixing smooth muscle cells and fibroblasts. In practice, due to tissue shearing and mechanical compression, substrates are exposed to make a large number of "spindle" smooth muscle and fibroblasts. In this study, we improved the use of collagenase IV to remove the corpus cavernosum cells from the white membrane. Collagenase IV contains low pancreatin activity, which slightly digests multiple tissues and minimizes cell membrane damage. The CD31 labeled immunomagnetic beads were used for sorting. CD31, also known as Platelet endothelial cell adhesion molecule-1 (PECAM-1), is expressed in tight junctions between cell membranes such as vascular endothelial cells and platelets, and endothelial cells. vWF is synthesized 


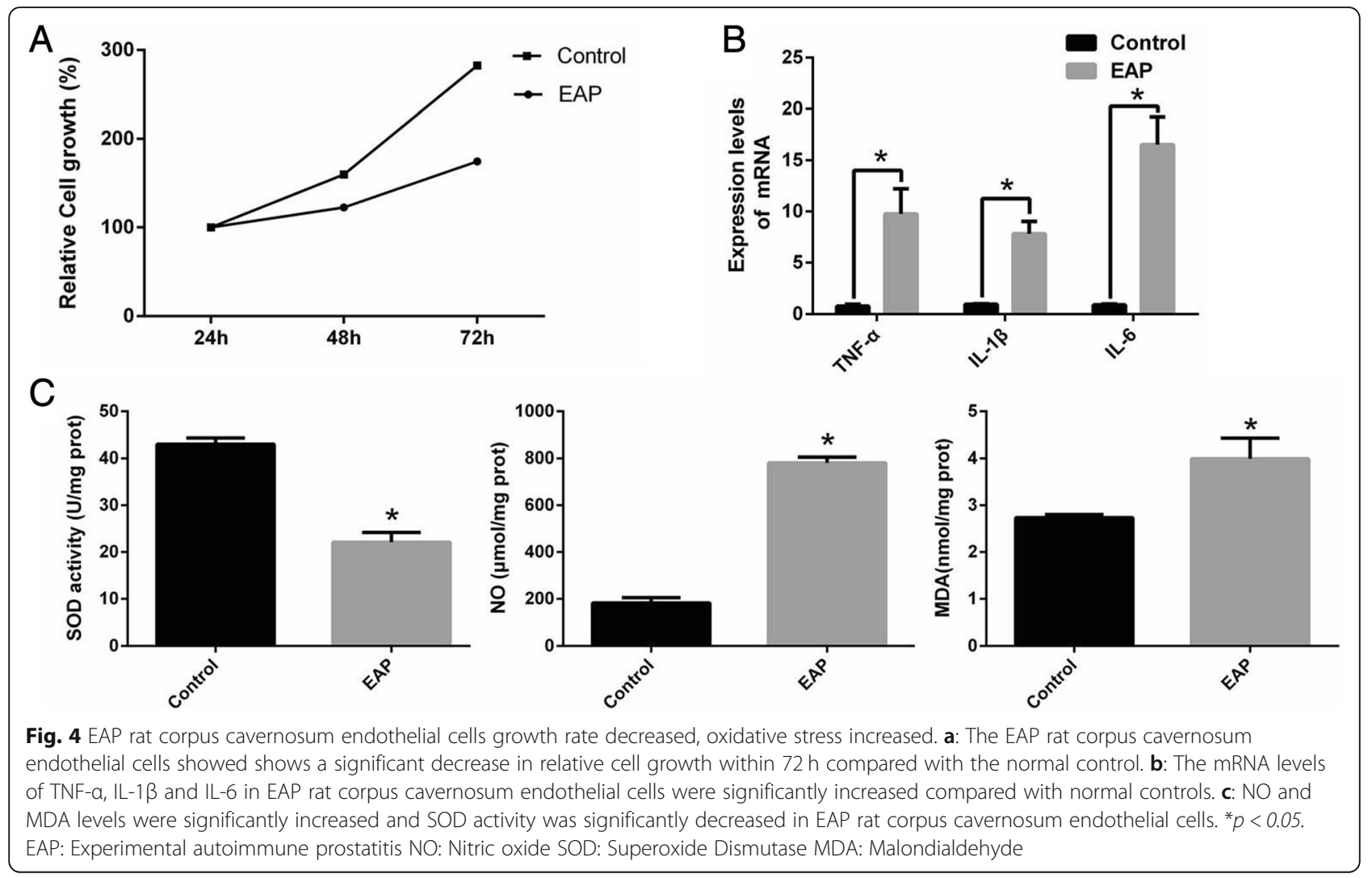

and secreted by vascular endothelial cells, which are mainly expressed in the cytoplasm of endothelial cells. Desmin and CD90/Thy1 which were strongly expressed in smooth muscle and fibroblast cells. In this study, we found that CD31 and vWF were highly expressed by cell immunofluorescence, and CD31 was mainly expressed on the cell membrane, VWF was mainly expressed in the cytoplasm, which also met the corresponding protein localization of CD31 and vWF. And Western blotting showed cells after MACS lack the band of Desmin and
CD90 / Thy1, which means MACS discharged the mixed smooth muscle and fibroblast cells effectively.

In this study, we first constructed an EAP rat model, and the prostate histopathology of EAP rats met the diagnostic criteria for simulating human CP/CPPS. In the previous study, Hu etal has reported a significant increase in inflammatory mediators and corpus cavernosum oxidative stress in EAP rats, and the erectile function of EAP rats is significantly reduced [12]. In this study, we further examined the expression of androgen
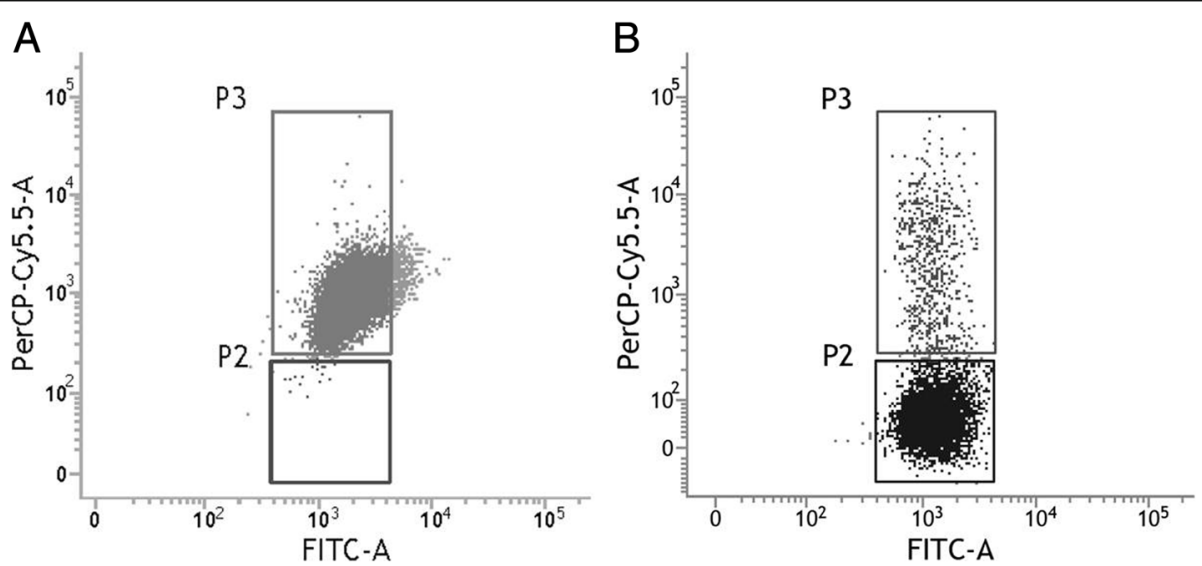

Fig. 5 The mitochondrial membrane potential of EAP rat corpus cavernosum endothelial cells was significantly decreased. a: normal control rat corpus cavernosum endothelial cells. b: EAP rat corpus cavernosum endothelial cells 

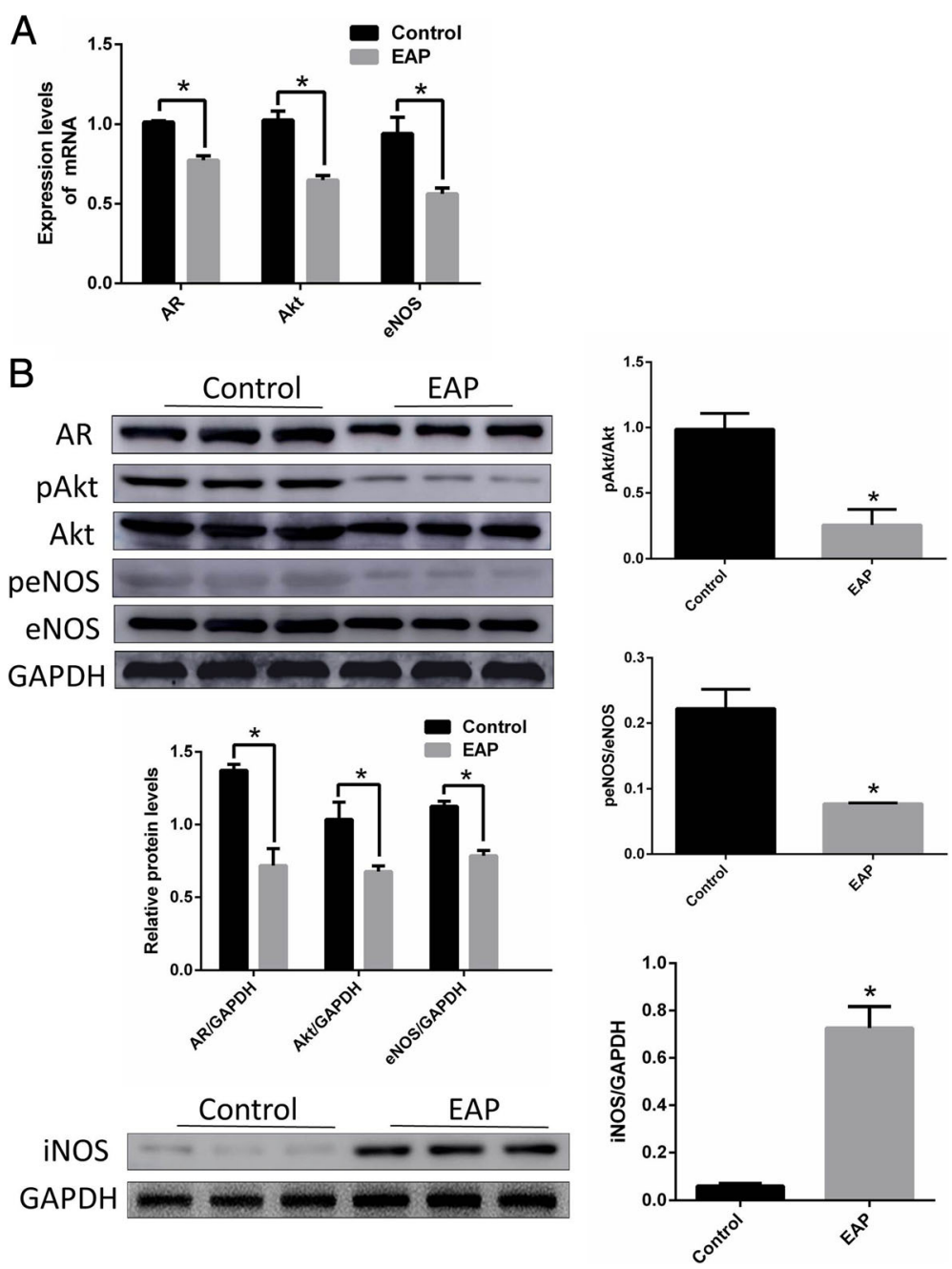

Fig. 6 Expression of AR, eNOS, AKt mRNA and protein in corpus cavernosum endothelial cell. a: The expression level of AR, eNOS and AKt mRNA were significantly decreased in EAP rat corpus cavernosum endothelial cell group compared with control. $\mathbf{b}$ : The expression level of AR, eNOS and AKt protein were significantly decreased, and iNOS were significantly increased in EAP rat corpus cavernosum endothelial cell group compared with control. And Western blot was normalized to GAPDH. ${ }^{*} p<0.05$. AR: Androgen receptor EAP: Experimental autoimmune prostatitis eNOS: endothelial nitric oxide synthase iNOS: inducible Nitric-Oxide Synthase

receptor, Akt, and endothelial nitric oxide synthase in the corpus cavernosum of EAP rats. Compared with normal control rats, Akt and endothelial oxidative in EAP rats. The down-regulation of nitrogen synthase and androgen receptors suggests a decrease in the function of penile cavernous endothelial cells in prostatitis rats.

In this study, we found that the levels of SOD and MDA in EAP purified endothelial cells were significantly higher than control. SOD is superoxide dismutase, which can specifically remove free radicals in the body to relieve the damage caused by free radical oxidation; MDA is Malondialdehyde, which is the final metabolite of lipid oxidation, causing toxic stress in cells. The electrophilic reaction reflects the degree of lipid oxidation of the cell membrane [22], the decrease in SOD level and the increase in MDA levels clearly reflect the increased degree of oxidative stress in the corpus cavernosum and endothelial cells.

Increased TNF- $\alpha$ infiltration was showed in EAP rat corpus cavernosum. We also found the mRNA levels of TNF- $\alpha$, IL- $1 \beta$ and IL- 6 in EAP corpus cavernosum endothelial cells were also significantly increased, and the metabolism of endothelial cells is significantly reduced. TNF- $\alpha$ can increase monocyte-macrophage capacity, activate NF- $\mathrm{BB}$ pathway to mediate inflammatory cascade, promote adhesion of various adhesion factors such as ICAM-1, and promote adhesion between neutrophils and endothelial cells [23], IL-1 $\beta$ is one of the most potent inflammatory factors. As a pro-inflammatory cytokine, IL- $1 \beta$ aggravates pain, edema and other reactions by promoting the expression of COX-2, 
iNOS and ICAM, and interacting with various inflammatory factors [24].

NO synthesized and released from cavernous endothelial cells by eNOS is an important factor in penile erection, which involved Akt-eNOS-cGMP pathway [25]. In this study, we reported eNOS was decreased significantly both in EAP rat corpus cavernosum and corpus cavernosum endothelial cells combined with lower max ICP/ MAP ratio. Akt is a serine/threonine protein kinase that also regulates phosphorylation of e-NOS Ser1177 in endothelial cells to produce NO, activates guanylate cyclase, and subsequently synthesizes cGMP, which activates cGMP-dependent calcium ions. The pathway reduces intracellular calcium ions, resulting in relaxation and erection of cavernous smooth muscle cells. eNOS phosphorylation is an important step in the production of NO by eNOS after protein translation. The downregulation of phosphorylation of Akt and eNOS inhibitied endothelial-dependent vasodilation and aggravating the degree of vasoconstriction and sclerosis $[10,11,26]$. In this study, we found iNOS get significant increased both in EAP rat corpus cavernosum and corpus cavernosum endothelial cells, and the level of NO in the corpus cavernosum endothelial cells of EAP rats was elevated, which was mainly caused by iNOS synthesis. In addition to eNOS, iNOS can also produce NO, but iNOS is not expressed in normal physiology, and its expression is usually induced by pathological stimulation such as cytokines. And unlike eNOS, which is mainly involved in the synthesis of physiologically optimal levels of $\mathrm{NO}$ and maintains normal physiological functions of endothelial cells, iNOS is almost 6-10 times more active than eNOS. iNOS rapidly produces high levels of NO when stimulated by various inflammatory stimuli [27]. A large amount of $\mathrm{NO}$ reacts with superoxide to produce peroxynitrite, causing lipid peroxidation and DNA. Cytotoxic reactions such as damage lead to cell and tissue damage [28]. Anti-inflammatory treatment could reduced the expression of iNOS in human umbilical vein endothelial cells [29], and endothelial dysfunction get ameliorated via inhibiting iNOS expression [30].

Mitochondria are the main synthetic organelles of ATP and are important sites for energy supply in the body. Synthetic ATP is exchanged into the cytoplasm by $\mathrm{ADP} / \mathrm{ATP}$ vectors in the mitochondrial inner membrane and ADP in the cytoplasm. During the process of respiratory oxidation, mitochondria store the energy generated by electrochemical potential energy in the mitochondrial inner membrane, causing asymmetric distribution of proton and other ion concentrations on both sides of the inner membrane to form mitochondrial membrane potential. Normal MMP is a prerequisite for maintaining mitochondrial oxidative phosphorylation and producing ATP. The stability of MMP is beneficial to maintain the normal physiological function of cells. The decrease of MMP marks the abnormality of cell energy metabolism and is the earliest signal of apoptosis [31]. Wang XJ and other scholars used projection electron microscopy to observe the corpus cavernosum of chronic nonbacterial prostatitis rats, and found a large number of mitochondria to moderate to severe swelling, and the mitochondrial inner membrane and outer membrane were destroyed [32]. Under the condition of oxidative stress, the oxygen free radicals can be promoted. When SOD can not effectively remove these oxygen free radicals, the excess oxygen free radicals can directly or indirectly damage the mitochondrial membrane, causing the MMP to decrease, leading to the inhibition of ATP synthesis. Metabolism eventually accelerates apoptosis. In this study, the Mitochondrial membrane potential (MMP) of penile cavernous endothelial cells was significantly reduced.

Previous studies reported that there is no significant changes in serum testosterone levels in CP/CPPS [12, 32, 33]. Our study found that AR decreased in EAP rat and in corpus cavernosum endothelial cell, and AR expression reduced greatly reduce the bioavailability of androgens [34]. Khalili $M$ etal found a significant decrease in AR expression in infected prostate glands by preparing a bacterial prostatitis model [35], and very low TNF$\alpha$ and IL-1 $\beta$ exposure can also lead to inhibition of the androgen receptor pathway [36, 37]. The AR antagonist flutamide, can significantly inhibit the proliferation, migration and colony formation of endothelial cells [38]. Testosterone and dihydrotestosterone combined with AR can up-regulate the expression of VEGF-A, cyclin A, and cyclin D1 to promote endothelial cell proliferation and help repair endothelial cells in the inflammatory environment [39].

\section{Conclusion}

The prostate suffer local inflammatory infiltrate and promotes the release of cytokines infiltrated into corpus cavernosum. Besides,the oxidative stress increases and the metabolism or MMP decreases significantly. In addition, AR, Akt and eNOS expression and phosphorylation are also reduced, thereby inhibiting the diastolic function of the corpus cavernosum, resulting in decreased erectile function.

\section{Abbreviations}

AR: Androgen receptor; CGMP : Cyclic guanosine monophosphate; CP/ CPPS: Chronic prostatitis/chronic pelvic pain syndrome;

DAB: Diaminobenzidine; EAP: Experimental autoimmune prostatitis; ED: Erectile dysfunction; EDR: Endothelium-dependent vasorelaxation; eNOS: endothelial nitric oxide synthase; ICAM: Intercellular cell adhesion molecule; ICP: Intracavernosal pressure; iNOS: inducible Nitric-Oxide Synthase; MACS: magnetic activated cell sorting; MACS: Magnetic-activated cell sorting; MAP: Mean arterial pressure; MDA: Malondialdehyde; MMP: Mitochondrial membrane potential; nNOS: neuronal nitric oxide synthase; NO: Nitric oxide; 
PTHS: Prostate tissue homogenate supernatant; SOD: Superoxide Dismutase; WF: Von Willebrand factor

\section{Acknowledgements}

Not applicable

\section{Authors' contributions}

Performed the experiment and the analysis: Tr Huang, Yy Hu, H Shi and L Yin. Wrote the Manuscript: Tr Huang, Gc Wang and L Yin. Design the experiment: Ky Wang, L Yin and B Peng. All authors read and approved the final manuscript.

\section{Funding}

This study was financially supported by Shanghai Municipal Commission of Health and Family Planning (Grant No. 20174Y0237), Shanghai Science and Technology Commission (Grant No.18140900302) and the National Natural Science Foundation of China (81870517).

\section{Availability of data and materials}

Please contact author for data requests.

\section{Ethics approval}

All procedure approved by the Animal Science Committee of Tongji University.

\section{Consent for publication}

Not applicable.

\section{Competing interests}

The authors declare that they have no competing interests.

\section{Received: 6 March 2019 Accepted: 2 July 2019}

Published online: 25 July 2019

\section{References}

1. Potts J, Payne RE. Prostatitis: infection, neuromuscular disorder, or pain syndrome? Proper patient classification is key. Cleve Clin J Med. 2007; 74(Suppl 3):S63-71.

2. Schaeffer AJ, Datta NS, Fowler JE Jr, Krieger JN, Litwin MS, Nadler RB, Nickel JC, Pontari MA, Shoskes DA, Zeitlin SI, et al. Overview summary statement. Diagnosis and management of chronic prostatitis/chronic pelvic pain syndrome (CP/CPPS). Urology. 2002;60:1-4.

3. McNaughton Collins M, Pontari MA, O'Leary MP, Calhoun EA, Santanna J, Landis JR, Kusek JW, Litwin MS, Chronic prostatitis collaborative research N. Quality of life is impaired in men with chronic prostatitis: the chronic prostatitis collaborative research network. J Gen Intern Med. 2001;16:656-62.

4. Lee SW, Liong ML, Yuen KH, Leong WS, Cheah PY, Khan NA, Krieger JN. Adverse impact of sexual dysfunction in chronic prostatitis/chronic pelvic pain syndrome. Urology. 2008;71:79-84.

5. Li HJ, Kang DY. Prevalence of sexual dysfunction in men with chronic prostatitis/chronic pelvic pain syndrome: a meta-analysis. World J Urol. 2015; 34:1009-17.

6. Chung SD, Keller JJ, Lin HC. A case-control study on the association between chronic prostatitis/chronic pelvic pain syndrome and erectile dysfunction. BJU Int. 2012;110:726-30.

7. Abeysinghe HR, Clancy J, Qiu Y. Comparison of endothelin-1-mediated tissue tension and calcium mobilization effects in isolated rabbit corpus cavernosum. Urology. 2002;60:925-30.

8. Pilatz A, Schultheiss D, Gabouev Al, Schlote N, Mertsching H, Jonas U, Stief CG. Isolation of primary endothelial and stromal cell cultures of the corpus cavernosum penis for basic research and tissue engineering. Eur Urol. 2005; 47:710-8 discussion 718-719.

9. Shoskes DA, Prots D, Karns J, Horhn J, Shoskes AC. Greater endothelial dysfunction and arterial stiffness in men with chronic prostatitis/chronic pelvic pain syndrome--a possible link to cardiovascular disease. J Urol. 2011; 186:907-10.

10. Zhang DX, Zou AP, Li PL. Ceramide-induced activation of NADPH oxidase and endothelial dysfunction in small coronary arteries. Am J Physiol Heart Circ Physiol. 2003;284:H605-12.
11. Zheng T, Li W, Wang J, Altura BT, Altura BM. Sphingomyelinase and ceramide analogs induce contraction and rises in [ca (2+)](i) in canine cerebral vascular muscle. Am J Physiol Heart Circ Physiol. 2000;278:H1421-8.

12. Hu Y, Dong $X$, Wang G, Huang J, Liu M, Peng B. Five-Year Follow-Up Study of Transurethral Plasmakinetic Resection of the Prostate for Benign Prostatic Hyperplasia. J Endourol. 2016;30:97-101.

13. Zhang H, Li F, Li WW, Stary C, Clark JD, Xu S, Xiong X. The inflammasome as a target for pain therapy. Br J Anaesth. 2016;117:693-707.

14. Jang TL, Schaeffer AJ. The role of cytokines in prostatitis. World J Urol. 2003; 21:95-9.

15. Shoskes DA. The challenge of erectile dysfunction in the man with chronic prostatitis/chronic pelvic pain syndrome. Curr Urol Rep. 2012;13:263-7.

16. Anderson RU, Orenberg EK, Morey A, Chavez N, Chan CA. Stress induced hypothalamus-pituitary-adrenal axis responses and disturbances in psychological profiles in men with chronic prostatitis/chronic pelvic pain syndrome. J Urol. 2009;182:2319-24.

17. Mehik A, Hellstrom P, Sarpola A, Lukkarinen O, Jarvelin MR. Fears, sexual disturbances and personality features in men with prostatitis: a populationbased cross-sectional study in Finland. BJU Int. 2001:88:35-8.

18. Aubin S, Berger RE, Heiman JR, Ciol MA. The association between sexual function, pain, and psychological adaptation of men diagnosed with chronic pelvic pain syndrome type III. J Sex Med. 2008;5:657-67.

19. Sattar AA, Schulman CC, Wespes E. Objective quantification of cavernous endothelium in potent and impotent men. J Urol. 1995;153:1136-8.

20. Carson MP, Saenz de Tejada I, Goldstein I, Haudenschild CC. Culture of human corpus cavernosum endothelium. In Vitro Cell Dev Biol. 1989;25: 248-54.

21. Pilatz A, Schultheiss D, Gabouev Al, Schlote N, Mertsching H, Jonas U, Stief CG. In vitro viability of human cavernosal endothelial and fibroblastic cells after exposure to papaverine/phentolamine and prostaglandin E1. BJU Int. 2005;95:1351-7.

22. Yu W, Wan Z, Qiu XF, Chen Y, Dai YT. Resveratrol, an activator of SIRT1, restores erectile function in streptozotocin-induced diabetic rats. Asian J Androl. 2013;15:646-51.

23. Mehta JL, Li D. Identification, regulation and function of a novel lectin-like oxidized low-density lipoprotein receptor. J Am Coll Cardiol. 2002;39:1429-35.

24. Hahn EL, Gamelli RL. Prostaglandin E2 synthesis and metabolism in burn injury and trauma. J Trauma. 2000:49:1147-54.

25. Prieto D. Physiological regulation of penile arteries and veins. Int J Impot Res. 2008:20:17-29.

26. Li H, Junk P, Huwiler A, Burkhardt C, Wallerath T, Pfeilschifter J, Forstermann $U$. Dual effect of ceramide on human endothelial cells: induction of oxidative stress and transcriptional upregulation of endothelial nitric oxide synthase. Circulation. 2002;106:2250-6.

27. Nagpal L, Panda K. Characterization of calmodulin-free murine inducible nitric-oxide synthase. PLoS One. 2015;10:e0121782.

28. Dinarello CA. Proinflammatory cytokines. Chest. 2000;118:503-8.

29. Zheng F, Dong X, Meng X. Anti-inflammatory effects of Taraxasterol on LPSstimulated human umbilical vein endothelial cells. Inflammation. 2018;41: 1755-61.

30. Sun W, Gao Y, Ding Y, Cao Y, Chen J, Lv G, Lu J, Yu B, Peng M, Xu H, Sun Y. Catalpol ameliorates advanced glycation end product-induced dysfunction of glomerular endothelial cells via regulating nitric oxide synthesis by inducible nitric oxide synthase and endothelial nitric oxide synthase. IUBMB Life. 2019;1:1-16.

31. Haeberlein SL. Mitochondrial function in apoptotic neuronal cell death. Neurochem Res. 2004:29:521-30

32. Wang XJ, Xia LL, Xu TY, Zhang XH, Zhu ZW, Zhang MG, Liu Y, Xu C, Zhong S, Shen $\mathrm{ZJ}$. Changes in erectile organ structure and function in a rat model of chronic prostatitis/chronic pelvic pain syndrome. Andrologia. 2016;48:243-51.

33. Corona G, Isidori AM, Buvat J, Aversa A, Rastrelli G, Hackett G, Rochira V, Sforza A, Lenzi A, Mannucci E, Maggi M. Testosterone supplementation and sexual function: a meta-analysis study. J Sex Med. 2014;11:1577-92.

34. Blute M, Hakimian P, Kashanian J, Shteynshluyger A, Lee M, Shabsigh R. Erectile dysfunction and testosterone deficiency. Front Horm Res. 2009;37: 108-22.

35. Khalili M, Mutton LN, Gurel B, Hicks JL, De Marzo AM, Bieberich CJ. Loss of Nkx3.1 expression in bacterial prostatitis: a potential link between inflammation and neoplasia. Am J Pathol. 2010;176:2259-68.

36. Culig Z, Hobisch A, Herold M, Hittmair A, Thurnher M, Eder IE, Cronauer MV, Rieser C, Ramoner R, Bartsch G, et al. Interleukin 1beta mediates the 
modulatory effects of monocytes on LNCaP human prostate cancer cells. Br J Cancer. 1998;78:1004-11.

37. Debelec-Butuner B, Alapinar C, Varisli L, Erbaykent-Tepedelen B, Hamid SM, Gonen-Korkmaz C, Korkmaz KS. Inflammation-mediated abrogation of androgen signaling: an in vitro model of prostate cell inflammation. Mol Carcinog. 2014;53:85-97.

38. Foresta C, Zuccarello D, De Toni L, Garolla A, Caretta N, Ferlin A. Androgens stimulate endothelial progenitor cells through an androgen receptormediated pathway. Clin Endocrinol. 2008;68:284-9.

39. Cai J, Hong Y, Weng C, Tan C, Imperato-McGinley J, Zhu YS. Androgen stimulates endothelial cell proliferation via an androgen receptor/NEGF/ cyclin A-mediated mechanism. Am J Physiol Heart Circ Physiol. 2011;300: H1210-21.

\section{Publisher's Note}

Springer Nature remains neutral with regard to jurisdictional claims in published maps and institutional affiliations.

Ready to submit your research? Choose BMC and benefit from:

- fast, convenient online submission

- thorough peer review by experienced researchers in your field

- rapid publication on acceptance

- support for research data, including large and complex data types

- gold Open Access which fosters wider collaboration and increased citations

- maximum visibility for your research: over $100 \mathrm{M}$ website views per year

At BMC, research is always in progress.

Learn more biomedcentral.com/submissions 